\title{
RANCANG BANGUN SISTEM RACK IN DAN RACK OUT PMT OTOMATIS DI KUBIKEL 20 KV BERBASIS ARDUINO MEGA 2560 MENGGUNAKAN VTSCADA 11.2
}

\author{
Ratna Azizah Puteri ${ }^{1)}$, Arkhan Subari' ${ }^{2)}$, Dista Yoel Tadeus ${ }^{2)}$ \\ ${ }^{1)}$ Program Studi D-III Teknik Elektro, Sekolah Vokasi, Universitas Diponegoro \\ Jl. Prof. Soedarto, SH, Kampus Undip Tembalang, Semarang, Indonesia 50275 \\ ${ }^{2}$ Program Studi Str. Teknik Listrik Industri, Sekolah Vokasi, Universitas Diponegoro \\ Jl. Prof. Soedarto, SH, Kampus Undip Tembalang, Semarang, Indonesia 50275
}

\begin{abstract}
The 20 KV PMT (Circuit Breaker) is an important equipment for the reliability of electricity distribution. Therefore it must be maintained so that it is always in good condition with regular maintenance. Prior to maintenance, PMT is terminated from the bus bar, which is called the rack out process. After maintenance, the PMT is reconnected with the bus bar, which is called the rack in process. Usually, $20 \mathrm{KV}$ PMT rack in and rack out process in maintenance or disturbance is still using the manual method. The 20 KV PMT can only be racked in and racked out in one way, by turning the lever. The lever will rotate the bolt as a PMT rail. In the manual method, there is no system for monitoring the condition of the bus bar whether it is has electric-voltage or not. There is also no remote control that can rack in and rack out. So officers must ensure the conditions of PMT and bus bars are safe manually, before maintenance is carried out. This is quite troublesome and dangerous for officers. From these problems, in this research designed a system that could ensure the condition of the PMT and the bus bar was safe before the rack in and rack out process was carried out and could monitor and control the system remotely using SCADA. Rack-in and rack-out automation system using VTSCADA, using Ethernet Shield that has been connected with Arduino Mega. Ethernet is connected to a mini PC. The microcontroller pins will be connected to the relays that will turn or stop the motor. The rack in and rack out commands from VTSCADA will determine the rotation of the motor so that the PMT moves. The current sensor reads the current flow and detects interference. Interference detection will automatically make PMT Rack out. System testing shows that the process of racking out in a state of maintenance or disturbance can be carried out automatically controlled by VTSCADA. Current sensor works to detect the current flowing, so that it can detect PMT interference and perform automatic rack out. The rack-in process is also capable of being remotely controlled with VTSCADA. This makes it easier for officers to also become additional reliability of PMT in the $20 \mathrm{KV}$ cubicle.
\end{abstract}

Keywords: automation; circuit breaker; rack in; rack out; PMT; VTSCADA; Arduino Mega

\section{PENDAHULUAN}

PMT (Pemutus tenaga) $20 \mathrm{KV}$ merupakan peralatan peralatan proteksi jaringan listrik yang sangat penting dalam penyaluran energi listrik yang terletak di dalam kubikel pada Gardu Induk sistem distribusi[1]. Fungsi utamnya adalah menjaga peralatan-peralatan agar terhindar dari kerusakan akibat lonjakan arus ketika terjadi gangguan. Caranya adalah dengan memutus jaringan listrik yang terdapat gangguan dari jaringan utama, sehingga ganggau yang terjadi tidak berpengaruh pada jaringan yang lainnya. PMT $20 \mathrm{KV}$ harus memiliki keandalan yang tinggi dalam keadaan normal maupun bergangguan. Karena itu harus dijaga agar selalu dalam kondisi baik dengan perawatan berkala. Sebelum pemeliharaan, PMT harus diputus dari busbar, yang disebut proses rack out. Setelah pemeliharaan, PMT dihubungkan kembali dengan busbar, yang disebut dengan proses rack in.

Biasanya, proses rack in dan rack out PMT ketika dilakukan pemeliharaan atau ketika terjadi gangguan menggunakan metode manual. Dalam metode manual, tidak ada sistem untuk memantau kondisi barbus apakah memiliki tegangan listrik atau tidak. Juga tidak ada pengendali jarak jauh yang bisa melakukan rack in dan rack out tanpa harus petugas masuk ke kubikel. Jadi petugas harus memastikan kondisi PMT dan busbar aman secara manual, sebelum pemeliharaan dilakukan.

Rack in dan rack out PMT dapat dilakukan pada saat pemeliharaan PMT $20 \mathrm{KV}$ dan saat gangguan terjadi. Pada saat pemeliharaan, sebelum melakukan pengujian pemeliharaan pada PMT $20 \mathrm{KV}$ hal pertama yang harus dilakukan adalah memastikan keadaan PMT aman. Karena pemeliharaan melibatkan petugas langsung. Untuk itu, setelah PMT $20 \mathrm{KV}$ dipastikan dalam keadaan Off, PMT $20 \mathrm{KV}$ baru bisa di rack out untuk memastikan pole PMT tidak menempel dengan busbar. Setelah itu PMT bisa dikeluarkan oleh petugas dari kubikel untuk dilakukan pengujian pemeliharaan[2]. Setelah pengujian pemeliharaan selesai, PMT akan dimasukkan kembali ke dalam kubikel. Dari keadaan rack out, PMT akan di rack in untuk memastikan pole PMT sudah menempel busbar. Selanjutnya PMT siap dinyalakan, sehingga PMT sudah siap pada saat kubikel digunakan dan diberi tegangan kembali.

Pada saat terjadi gangguan di lapangan, PMT $20 \mathrm{KV}$ akan memutus dan posisi akan otomatis off. Hal ini berguna untuk melindungi peralatan listrik 
dan keamanan sekitar PMT 20 KV dan kubikel. PMT baru akan di rack out setelah PMT dipastikan Off dan adanya indikator bahwa PMT aman untuk di rack out. Namun proses rack out terlebih dahulu menunggu petugas datang ke lapangan dan melakukan rack out dengan memutar pengungkit PMT $20 \mathrm{KV}$ di dalam kubikel bergangguan. Hal ini cukup beresiko karena untuk memastikan pole PMT bergangguan tidak menempel pada busbar harus petugas yang melakukan.

Sehingga untuk menambah keandalan PMT dibutuhkan sistem otomatisasi yang dapat dikendalikan jarak jauh berbasis SCADA[3]. Pentingnya sistem monitoring ini untuk mengetahui keadaan PMT jarak jauh. Selain itu indikator PMT rack in dan rack out sangat dibutuhkan untuk memastikan keadaan aman sebelum melakukan pekerjaan pemeliharaan[4]. Monitoring juga sangat dibutuhkan pada saat gangguan, untuk memastikan PMT aman dalam keadaan off dan telah dilakukan rack out otomatis, sebelum petugas melakukan evaluasi gangguan[5].

\section{METODE PENELITIAN}

Sistem otomatisasi rack in dan rack out PMT 20 KV dirancang menggunakan Arduino Mega 2560. Arduino merupakan modul yang dirancang berdasarkan rangkaian mikrokontroler yang siap digunakan[6,7]. Dengan modul yang fleksibel dan mudah digunakan[8], banyak orang yang telah menggunakan Arduino untuk proyek otomatisasi. Pin-pin pada Arduino akan tersambung dengan relai $5 \mathrm{~V}$ yang akan memutar atau menghentikan motor ketika proses rack in dan rack out dilakukan. Indikator status PMT ditampilkan menggunakan lampu AC $220 \mathrm{~V}$ yang dikendalikan melalui relai. Sedangkan indikator rack in dan rack out dapat dilihat melalui lampu DC $12 \mathrm{~V}$ yang dikendalikan oleh relai dan dipicu oleh kondisi limit switch. Sistem pengendalian jarak jauh dirancang dengan menggunakan VTSCADA. VTSCADA dapat melakukan monitoring dan pengendalian alat secara jarak jauh dan menampilkan hasil monitoring pada aplikasi berbasiskan web[7,14]. Pengiriman data pada VTSCADA menggunakan Ethernet Shield yang telah disambungkan dengan Arduino Mega[9]. Ethernet tersambung dengan mini PC. VTSCADA akan memberikan perintah rack in dan rack out yang akan diterjemahkan dengan melakukan putaran motor[10] yang terhubung melalui relai.

Otomatisasi rack in dan rack out PMT $20 \mathrm{KV}$ dapat dilakukan pada saat proses pemeliharaan dan gangguan. Alat dibuat untuk memudahkan dan pengamanan proses, bisa dikendalikan dari sistem jarak jauh menggunakan VTSCADA.

Gambar rangkaian rack out ditunjukkan pada Gambar 1. PMT dapat dinyalakan dan dimatikan melalui pin 23 dan 25 arduino, sedangkan statusnya dibaca melalui kondisi pada pin 22 dan 24 arduino. Motor penggerak dikendalikan oleh arduino melalui pin 47 yang kondisi sinyalnya tergantung dari kondisi limit switch yang terhubung dengan pin 40 arduino. Pada proses rack out, relai akan close dan menggerakkan motor. Putaran motor akan bergerak ke kiri sehingga roda PMT akan ke luar kubikel. Relai akan kembali open saat sensor limit switch bagian depan close, menandai PMT sudah di posisi rack out. Saat itu motor akan berhenti berputar. Apabila terjadi gangguan atau PMT dalam keadaan kelebihan arus, sistem akan melakukan rack out secara otomatis setelah memutus PMT. Arus PMT dipantau menggunakan sensor arus ZMCT103. Ketika terjadi gangguan, sensor arus pada PMT akan mendeteksi adanya kelebihan arus (lebih dari 0,85 A)[11] sehingga mengakibatkan PMT trip dan memicu relai bekerja dan motor akan otomatis berputar ke kiri dan menggerakkan roda PMT menuju luar kubikel. Motor akan berhenti berputar setelah limit switch bagian depan PMT mendeteksi dan relai berubah menjadi open[12]. Fllowchart proses rack out ditunjukkan pada Gambar 2.

Rancangan proses rack in ditunjukkan pada Gambar 3. Putaran motor ke dalam kubikel dikendalikan oleh relai yang terhubung dengan pin 45 dan 47 arduino. Sedangkan penghentian putaran motor dilakukan melalui kondisi limit switch yang terhubung dengan pin 42 arduino. Pada proses rack in, relai pembalik putaran bekerja dan motor akan otomatis berputar ke kanan dan menggerakkan roda PMT menuju ke dalam kubikel. Relai akan kembali open saat sensor limit switch bagian belakang mendeteksi, menandai steker pole atas sudah masuk ke stop kontak. Saat itu juga motor akan berhenti berputar. Indikasi juga akan terbaca pada VTSCADA dalam keadaan PMT on/off dan rack in/out[13]. Flowchart proses rack in ditunjukkan pada Gambar 4.

Pengendalian jarak jauh memungkinkan pengoperasian alat dalam proses rack in dan rack out dilakukan di ruang dispatcher. Sehingga petugas lapangan tidak melakukan kontak langsung dengan peralatan. Hal ini akan menambah faktor keselamatan dan dapat mengurangi kesalahan kerja.

Sistem ini dilengkapi Sensor Arus yang digunakan sebagai pendeteksi arus yang mengalir pada alat hingga 5 A. Koil induksi pada sensor akan mendeteksi perubahan medan magnet yang terjadi di sekeliling konduktor pembawa arus. Dengan mengukur jumlah arus yang dibangkitkan oleh koil induksi dapat dihitung jumlah arus yang melewati konduktor tersebut (Prinsip medan magnet pada trafo).

Sensor ini membutuhkan VCC sebesar 5 VDC. Koil dihubungkan dengan rangkaian beban dan output ke pin analog Arduino. Di dalam Arduino, input berupa ADC dikonversi dalam bentuk bit yang kemudian diolah dengan program untuk dimunculkan dalam bentuk pembacaan tegangan secara realtime pada HMI. Gambar 5 merupakan rangkaian Sensor Arus ZMCT103C dengan beban. 


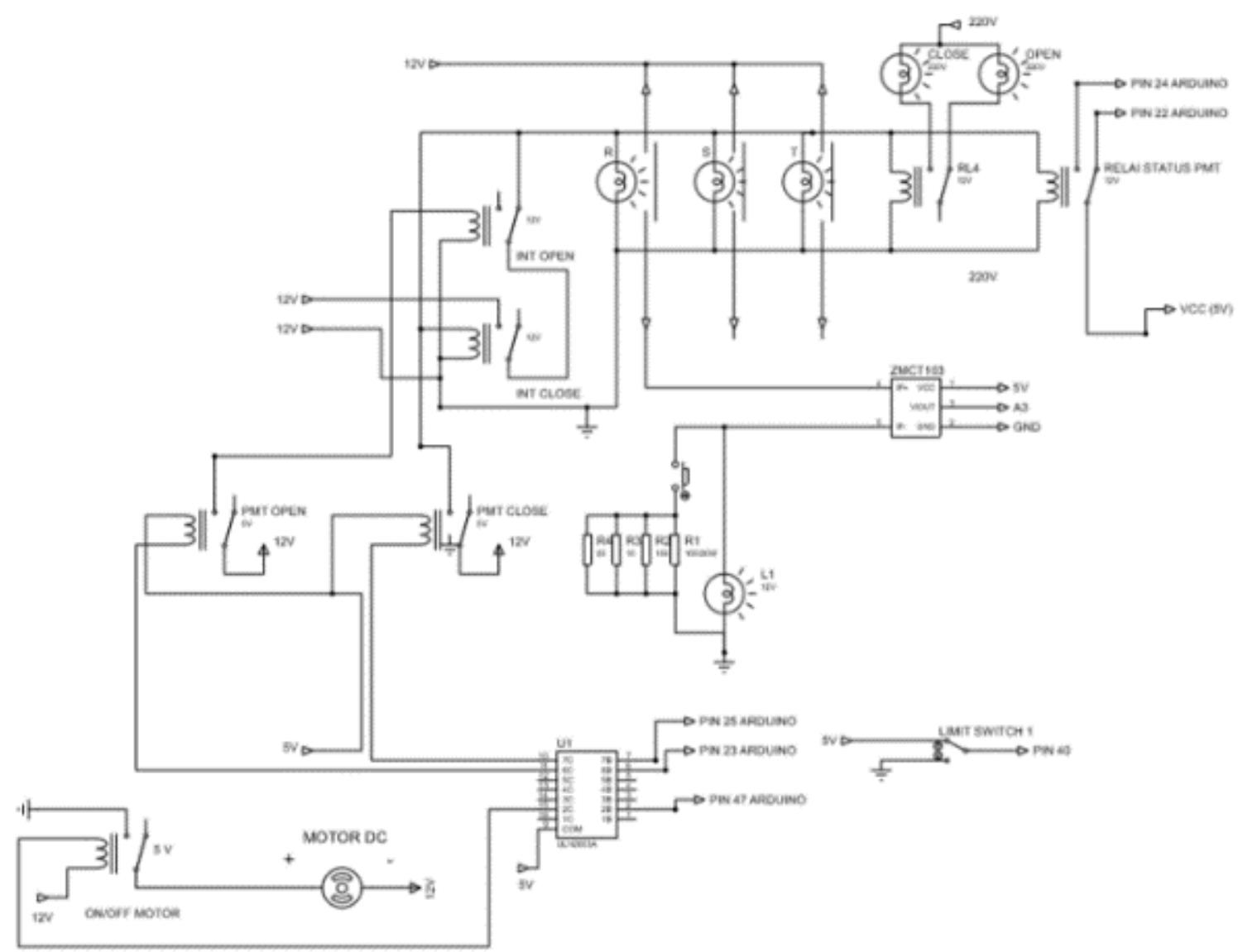

Gambar 1. Rangkaian Rack Out

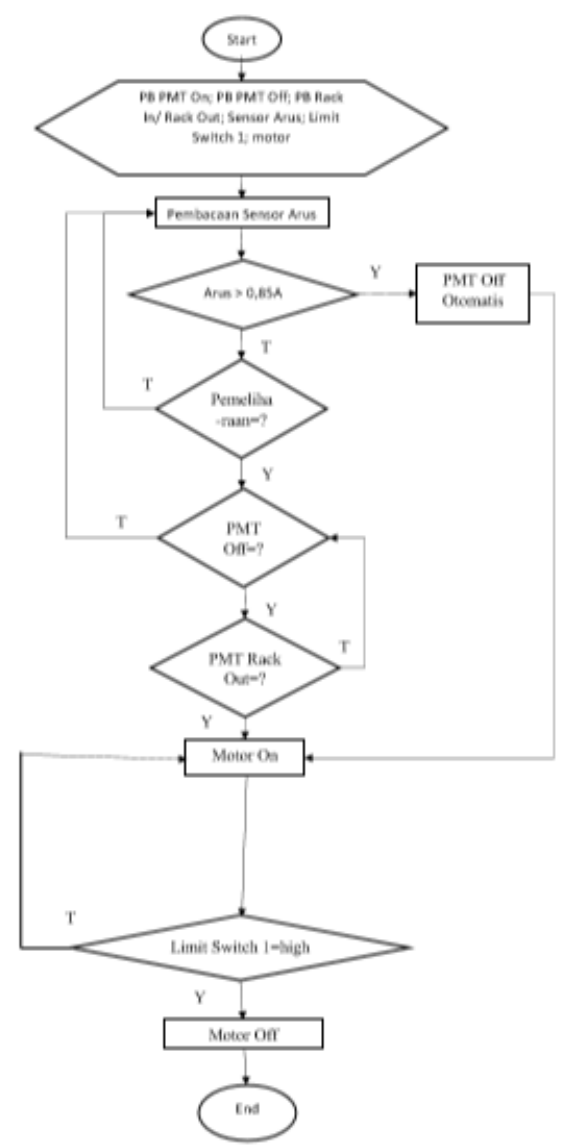

Gambar 1. Diagram Alir Rack Out 


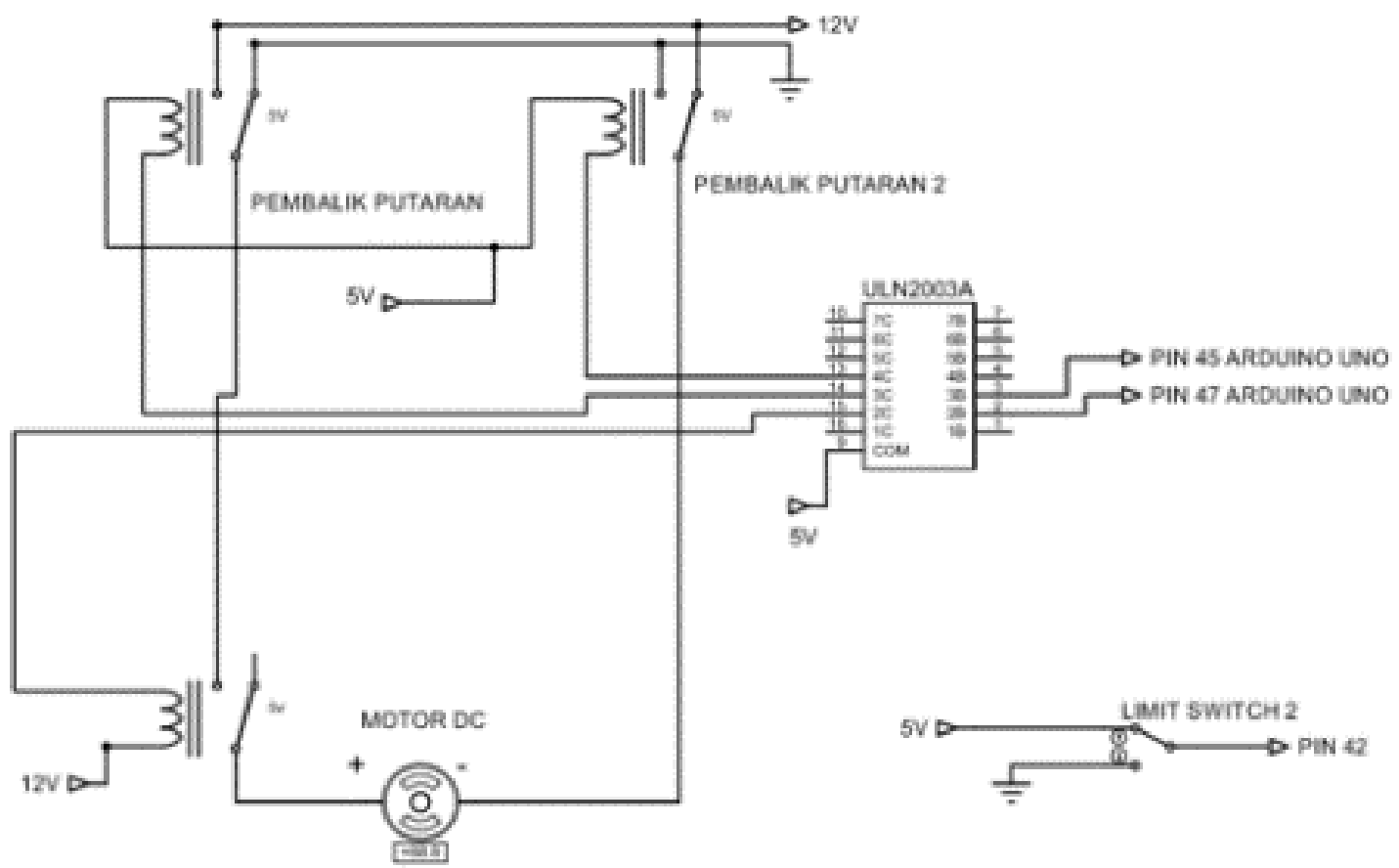

Gambar 2. Rangkaian Rack In

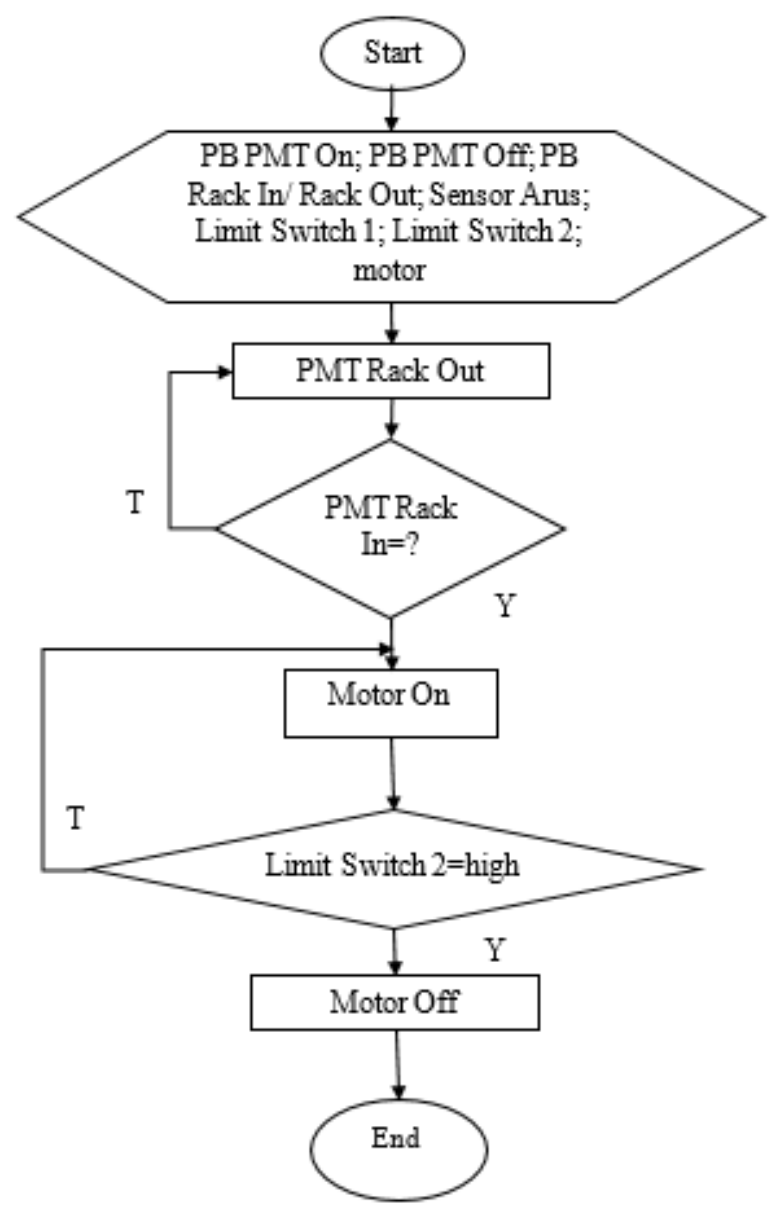

Gambar 3. Diagram Alir Rack Out 


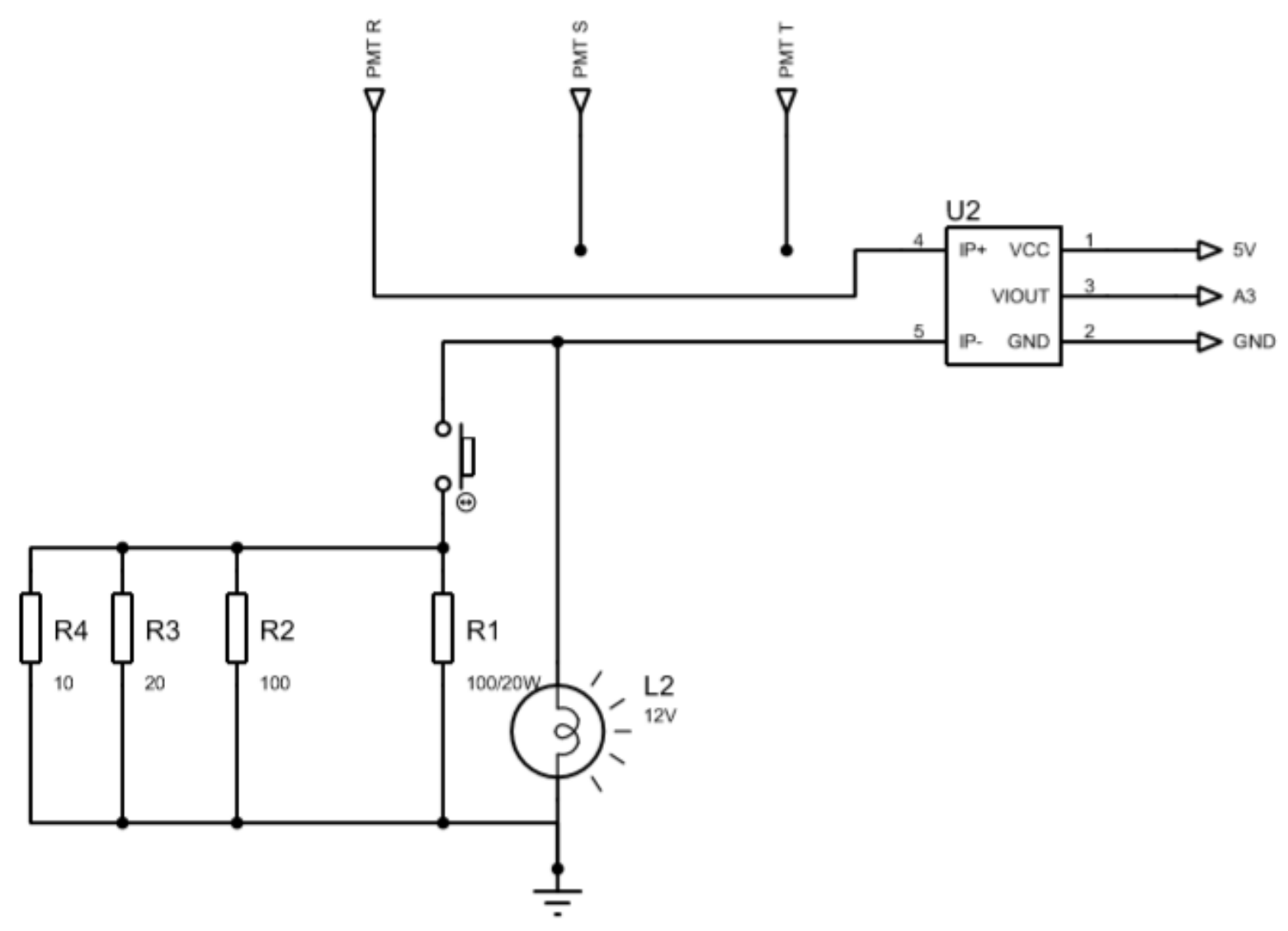

Gambar 4. Rangkaian Beban dan Sensor Arus ZMCT103C

\section{HASIL DAN PEMBAHASAN}

Pengujian rack out otomatis dilakukan dengan dua proses yaitu proses pemeliharaan dan gangguan.

Tabel 1. Hail pengujian Rack Out saat pemeliharaan

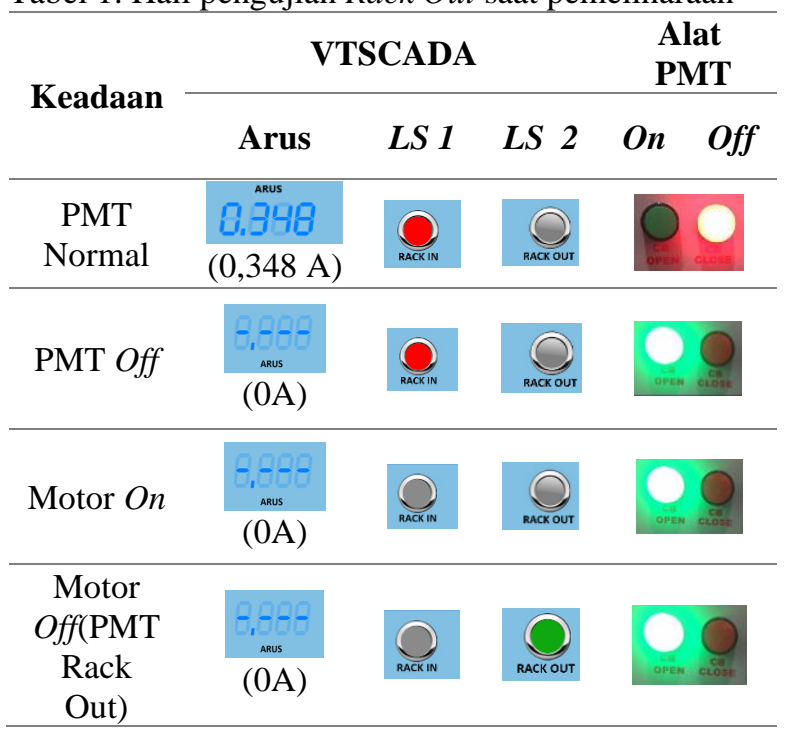

Pada saat pemeliharaan, pengujian dilakukan dari VTSCADA. Langkah pertama adalah mematikan PMT dengan cara menekan tombol yang disediakan, sehingga indikator PMT dalan kondisi open.
Kemudian menekan tombol rack out pada VTSCADA sehingga Arduino mega akan memicu relai motor untuk ON dan proses rack out dijalankan. Hasil pengujian dari pengujian rack out pada saat pemeliharaan ditunjukkan pada tabel 1 .

Dari table 1 didapatkan bahwa ketika proses rack out, kondisi PMT harus dalam kondisi off (arus 0 A). Hal ini penting dilakukan untuk menjaga peralatan agar tidak terganggu fungsinya. Proses rack out selesai dilakukan ketika indikator rack out pada limit switch menyala, yang menandakan bahwa PMT sudah benar-benar terputus dari busbar. Dalam kondisi ini petugas dapat melepas dan melakukan pemeliharaan PMT dengan aman.

Pengujian rack out pada saat gangguan dilakukan dengan menekan tombol gangguan pada VTSCADA. Aktifnya tombol gangguan akan memberikan arus lebih pada beban yang melebih arus normal sebesar $0,85 \mathrm{~A}$, seperti yang ditunjukkan pada Tabel 2. Akibatnya arduino mega akan memicu relai PMT Off kemudian akan melakukan rack out. Hasil pengujian dari pengujian rack out pada saat gangguan ditunjukkan pada tabel 3. 
Tabel 2. Pengujian Arus

\begin{tabular}{|c|c|c|}
\hline \multirow{2}{*}{ Pengujian } & \multicolumn{2}{|c|}{ Indikator } \\
\hline & Alat & VTSCADA \\
\hline Normal & 0 & $\frac{0,348}{(0,348 \mathrm{~A})}$ \\
\hline $\begin{array}{c}\text { Gangguan } \\
\text { Beban } \\
\text { PMT } \\
\text { ditekan }\end{array}$ & 0 & $\begin{array}{c}\text { ARus } \\
(0,978 \mathrm{~A})\end{array}$ \\
\hline PMT Trip & & $\begin{array}{l}\text { ARUS } \\
(0 \mathrm{~A})\end{array}$ \\
\hline
\end{tabular}

Tabel 3. Hasil pengujian Rack Out saat gangguan

\begin{tabular}{|c|c|c|c|c|}
\hline \multirow{2}{*}{ Keadaan } & \multicolumn{3}{|c|}{ VTSCADA } & $\begin{array}{c}\text { Alat } \\
\text { Indikator }\end{array}$ \\
\hline & Arus & $L S 1$ & $L S 2$ & On $\quad$ off \\
\hline $\begin{array}{l}\text { PMT } \\
\text { Normal }\end{array}$ & $\begin{array}{l}\text { anus } \\
(0,348 \mathrm{~A})\end{array}$ & 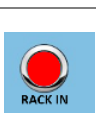 & & \\
\hline $\begin{array}{c}\text { Gangguan } \\
\text { Beban } \\
\text { PMT } \\
\text { ditekan }\end{array}$ & $\begin{array}{c}\text { ARus } \\
(0,978 \mathrm{~A})\end{array}$ & क्रवरा & & \\
\hline $\begin{array}{l}\text { Motor } \\
\text { ON }\end{array}$ & $\begin{array}{l}\text { ARus } \\
\text { (0A) }\end{array}$ & $\overbrace{\text { rackim }}$ & $\bigodot_{\text {тасти }}$ & \\
\hline $\begin{array}{l}\text { Motor } \\
\text { OFF } \\
\text { (PMT } \\
\text { Rack } \\
\text { Out) }\end{array}$ & (0A) & rackin & RACKout & \\
\hline
\end{tabular}

Dari table 2 dan table 3, ditunjukkan bahwa pada saat terjadi gangguan, sensor arus akan mendeteksi adanya arus lebih. Arus terdeteksi adalah 0,978 A sementara arus nominal pada PMT adalah 0,348 A. Hal ini akan mengakibatkan PMT trip dan memicu terjadinya rack out otomatis.

Pengujian sistem rack in dilakukan pada saat PMT posisi rack out dan status PMT sudah Off. Pengujian dengan cara mengklik tombol rack in pada VTSCADA sehingga Arduino mega akan memicu relai motor ON dan relai pembalik putaran high. Motor akan berputar menggerakkan PMT mundur, motor akan berhenti setelah limit switch 2 mendeteksi high. Hasil pengujian dari pengujian rack in ditunjukkan pada tabel 4.

Tabel 2. Hasil pengujian Rack In

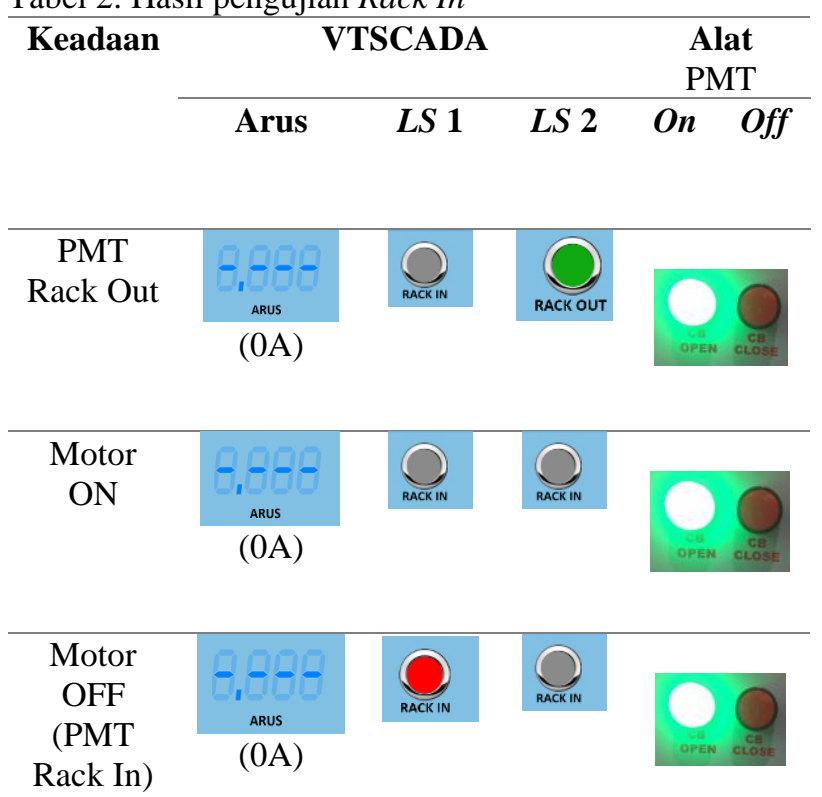

Proses rack in dilakukan saat kondisi PMT terputus. Prosesnya berhasil ketika indikator rack in menyala yang menandakan bahwa PMT sudah terhubung dengan busbar dan siap untuk dihidupkan.

Seluruh proses rack out dan rack in dilakukan secara remote menggunakan VTSCADA. Dengan demikian petugas tidak perlu kontak langsung dengan peralatan, sehingga prosesnya menjadi lebih aman.

\section{KESIMPULAN}

Setiap indikator lampu yang terhubung dengan VTSCADA saat setiap tombol button ditekan dapat memberikan informasi valid sehingga dapat terdeteksi oleh mikrokontroler Arduino Mega 2560 sesuai dengan status dari relay pada saat motor bekerja. Arus yang ditampilkan oleh VTSCADA sesuai dengan perngukuran pada alat. Pada saat gangguan arus mendeteksi lebih dari 0,85 A Arduino mampu memberikan trigger pada otomatisasi alat untuk melakukan rack out. Rack out dapat dilakukan secara otomatis dalam keadaan pemeliharaan maupun keadaan bergangguan dengan menggunakan VTSCADA 11.2. Serta Rack In dapat dikendalikan secara otomatis menggunakan VTSCADA 11.2.

\section{DAFTAR PUSTAKA}

1. Amelia, M.T., 2015. Evaluasi Penggunaan Pemutus Tenaga Pada Gardu Induk Bungaran Palembang, Doctoral dissertation, Politeknik Negeri Sriwijaya.

2. Pujotomo, I., 2016. Implementasi Sistem SCADA Untuk Pengendalian Jaringan Distribusi 20 KV. Jurnal Kajian Teknik Elektro, 1(1), pp.51-66. 
3. Saleh, M. and Haryanti, M., 2017. Rancang Bangun Sistem Keamanan Rumah Menggunakan Relay. Jurnal Teknologi Elektro, $8(2)$.

4. Lesmana, C., Lim, R. and Santoso, L.W., 2019. Implementasi Face Recognition menggunakan Raspberry pi untuk akses Ruangan Pribadi. Jurnal Infra, Vol 7(1), pp.63-66.

5. Nur, Anisa. 2018. Penggunaan Interface Dan Bus Riser Pada Kubikel 20kv Di Gardu Induk 150kv Krapyak. Laporan Kerja Praktik (Tidak diterbitkan). Yogyakarta: Universitas Gajah Mada.

6. R. Dewi, and A. Subari, 2012, Rancang Bangun Aplikasi Pengukuran Tinggi Badan, Berat Badan, Suhu Tubuh, Dan Tekanan Darah Berbasis Miktrokontroler ATMEGA16, Gema Teknologi, vol. 17, no. 1, pp. 43-52, Oct. 2012. https://doi.org/10.14710/gt.v17i1.8916.

7. M. R. Samputro, and A. Subari, 2019, Simulasi Pelimpahan Beban Sistem PMT Kopel To Kopel Pada Saat Pemeliharaan Trafo Berbasis Arduino Mega 2560 Menggunakan VT SCADA 11.2, Gema Teknologi, vol. 20, no. 3, pp. 74-79, Oct.

2019. https://doi.org/10.14710/gt.v20i3.25749.

8. G. Wohingati, and A. Subari, 2015, Alat Pengukur Detak Jantung Menggunakan Pulsesensor Berbasis Arduino Uno R3 Yang Diintegrasikan Dengan Bluetooth, Gema
Teknologi, vol. 17, no. 2, Aug. 2015. https://doi.org/10.14710/gt.v17i2.8919

9. Arduino \& Genuino Products, 2019, Getting Started with the Arduino Ethernet Shield.

10. Anshori, Y., 2009. Pengaturan Kecepatan Putaran Motor Dc Berbasis Komputer. MEKTEK, 11(2).

11. LC-Technology, 2019, 5A Current Sensor, LCTechnology

12. Kho, Dickson. TT., 2019, Pengertian Relay dan Fungsinya, teknikelektronika.com.

13. M. Gumelar B, and E. Ariyanto, 2017, Implementasi Scada Untuk Monitoring Dan Controling Serta Koordinasi Sistem Proteksi Gardu Induk Sistem 1,5 Breaker Pada Gardu Induk Tegangan Ekstra Tinggi Berbasis Arduino Mega 2560 Dengan Tampilan HMI, Gema Teknologi, vol. 19, no. 3, pp. 14-18, Oct. 2017.

14. D. Ashifa, and A. Subari, 2019, Simulasi Penentuan Lokasi Gangguan Satu Fasa Pada Jaringan Tegangan Menengah 20 KVBerbasis Arduino Mega 2560 Dilengkapi Dengan Monitoring Melalui VTScada,Gema Teknologi, vol. 20, no. 2, pp. 54-59, Apr. 2019. https://doi.org/10.14710/gt.v20i2.23097. 